\title{
Development of E-Dialysis Database Management System (DBMS) for Computer-Based Documentation and Mobile Application with RFID Technology
}

\author{
N. E. Kamaruzaman, I. Ismail
}

\begin{abstract}
This paper outlined the development of E-dialysis Database Management System (DBMS) for electronic-based documentation, which is applied to computer device and mobile application, integrated with RFID technology. Digital transformation of data is critical as it offers a better approach in documenting and storing the crucial medical records. Issues related to human error such as losing or misplacing the documents could be prevented and these records are more protected. The general system encompasses local and cloud databases, a computer Graphical User Interface (GUI) and a mobile application for normal dialysis patients. The system also includes $13.56 \mathrm{MHz}$ High Frequency (HF) RFID technology which is inferred as an effective life-saving solution for the smallest percent of the unfortunate dialysis patients who have disabilities or in the End Stage Renal Disease (ESRD). In a way, they can communicate with their doctors or caregivers just by simply providing their RFID tags that contain their medical records. Not only that, RFID technology was used for the purposes of patient identification and medical data tracking. The tags are scanned on RFID reader which is linked to the Database Management System (DBMS) that are developed with MYSQL. A PC Graphical User Interface (GUI), created with Visual Basic, and a mobile application using AppSheet act as the monitoring tools of this proposed research. A dialysis monitoring system integrated with Database Management System (DBMS) using RFID technology has been successfully developed to help and provide increased security and convenience for the users.
\end{abstract}

Index terms-dialysis patients, Database Management System, Graphical User Interface, local database, cloud database, mobile application, RFID technology, medical records

\section{INTRODUCTION}

$\mathrm{W}^{\mathrm{h}}$ hen the kidneys have permanently lost its function and fail to sustain human's life, this will cause a range of symptoms and abnormalities in organs to be occurred leading the patients to depend on dialysis. This is known as End Stage Renal Disease (ESRD) or now termed as Chronic Kidney Disease (CKD) Stage 5 [1]. In Malaysia, it is found that the prevalence of Chronic Kidney Disease (CKD) is about $9.07 \%$ of the total population, of which $0.36 \%$ of them are at stage 5 of CKD or End Stage Renal Disease (ESRD) [2].

This manuscript is submitted on $8^{\text {th }}$ September 2020 and accepted on $10^{\text {th }}$ November 2020. Nor Elysha Kamaruzaman and Ismarani Ismail are with the Faculty of Electrical Engineering, Universiti Teknologi MARA, 40450 Shah Alam, Selangor (e-mail: elyshakamaruzaman@gmail.com)

1985-5389/C 2021 The Authors. Published by UiTM Press. This is an open access article under the CC BY-NC-ND license (http://creativecommons.org/ licenses/by-nc-nd/4.0/)
Statistics from 24th Report of the Malaysian Dialysis and Transplant Registry 2016 indicates an upward pattern in the number of incident and prevalent patients for the last nine years since year 2007. The overall trend indicates that the aging population, ranging from $55-64$ to $>65$ years age groups, has a total domination over the highest treatment rates received compared to the other age groups [3]. There is a prominent difference in percentage which is about $9.25 \%$ of dialysis patients receiving their treatment between these two age groups. This inferred that the $>65$ age group was more susceptible to kidney failures. Generally, the Malaysia government has currently set 60 years old as an official retirement age [4]. The correlation suggests that the majority number of the dialysis patients receiving the treatments within those nine years were in their retirement age. The age group of 55-64 was the second highest after the age group of $>65$. In most cases, people in this age group usually hold positions in the executive management. Hence, this poses a problem to those who need to be in their best form leading an organization or a company and constantly travel on business trips and meetings.

TABLE 1

DIALYSIS TREATMENT RATES IN 10 YEARS (PER MILLION AGE GROUP POPULATION) [3]

\begin{tabular}{|c|c|c|c|c|c|c|c|c|c|c|}
\hline Age Year & 2007 & 2008 & 2009 & 2010 & 2011 & 2012 & 2013 & 2014 & 2015 & 2016 \\
\hline$<14$ & 6 & 6 & 8 & 7 & 7 & 6 & 7 & 6 & 7 & 7 \\
\hline $15-24$ & 32 & 30 & 35 & 28 & 30 & 34 & 42 & 42 & 39 & 36 \\
\hline $25-34$ & 60 & 70 & 71 & 77 & 78 & 83 & 86 & 91 & 93 & 94 \\
\hline $35-44$ & 119 & 146 & 134 & 154 & 169 & 187 & 203 & 210 & 231 & 217 \\
\hline $45-54$ & 352 & 393 & 400 & 458 & 505 & 536 & 536 & 570 & 584 & 546 \\
\hline $55-64$ & 760 & 759 & 813 & 906 & 998 & 1063 & 1091 & 1149 & 1167 & 1107 \\
\hline $64>$ & 853 & 975 & 1032 & 960 & 1115 & 1192 & 1162 & 1250 & 1275 & 1159 \\
\hline
\end{tabular}

Generally, a patient who undergoes hemodialysis treatment needs to visit a dialysis center or a hospital about three to five times a week, depending on the severity of the kidney failures. Commonly, when a dialysis patient needs to travel somewhere far from their regular center for a long period, they are required to be well-prepared. The patient should conduct several procedures which include arranging appointments with the new dialysis center and obtaining updated medical records and a referral letter from their regular-visited center. The major issue 
with this current method is the means of communication between the patient and the dialysis centers which are only email, fax and phone.

However, it is a whole different case when it comes to the smallest percentage of dialysis patients who have complications or disabilities such as bedridden, hearing or vocal impairment. These patients would have some difficulties to communicate with the new dialysis center's medical personnel or caretaker properly. In any emergency case especially when a dialysis patient suddenly loses consciousness, there is no way for the emergency team to obtain the information immediately, thereby delaying the treatment process which might worsen the patient's health.

The medical documents are usually documented in the paper form. This conventional documentation method is prone to be damaged and missed, and what is more, it does not have any backup capability. Additionally, the security of the medical records is paramount. A simple data logging into the computer or local database is inadequate. A poor security system of protecting these data will allow unauthorized access. Consequently, any unauthorized modification towards the data could contribute to errors in diagnosing and prescribing medications to the dialysis patients resulting severe harm to their health. For that matter, this would definitely affect the credibility and reputation of the hospitals or dialysis centers.

Hence, the objectives of this research are to create and develop a Database Management System (DBMS) including Graphical User Interfaces (GUIs) for information exchange between dialysis centers and its patients and develop a High Frequency (HF) RFID system which includes the RFID reader and antenna for tracking and tracing medical information of dialysis patients. RFID is synonymous with identification and track-and-trace solutions. It plays a vital role in numerous sectors including healthcare.

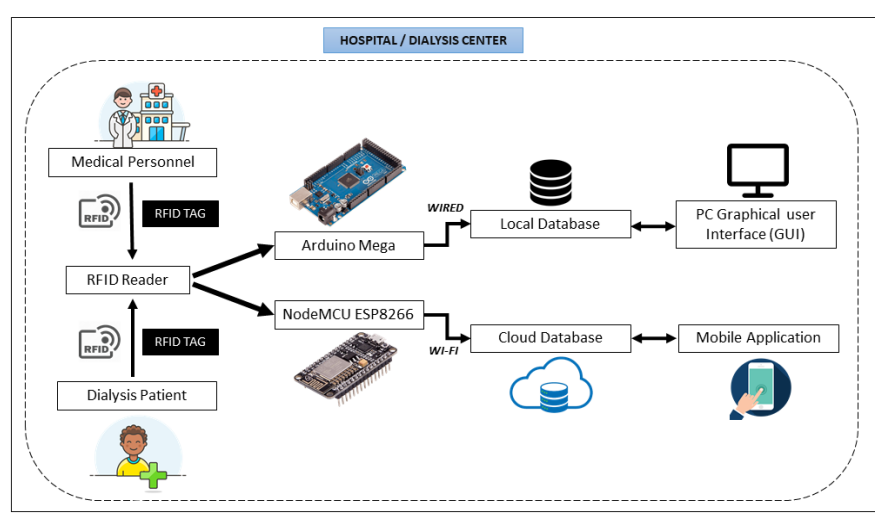

Fig. 1 E-Dialysis System Architecture

As shown in Figure 1, this research utilizes High Frequency (HF) MFRC522 RFID readers and passive tags. With the frequency of $13.56 \mathrm{MHz}$, an RFID reader can read the High Frequency (HF) tag within the safe reading distance of $3 \mathrm{~cm}$ approximately. This HF band is chosen for its short frequency rage to ensure that unauthorized readers cannot obtain the data from the tags. No battery is required for the RFID tags; hence they are smaller and more flexible to be carried anywhere. There are two main controllers used in the system which are Arduino Mega and NodeMCU ESP8266. Each controller is interfaced to their own RFID reader and database. As for Arduino Mega, the RFID reader communicates with Personal Computer (PC) that is linked to local database via a wired USB cable while for NodeMCU ESP8266, Wi-Fi is utilized to communicate with the mobile application that is connected to cloud database.

It must be highlighted that the system is to be implemented in multiple hospitals and dialysis centers. This means only authorized medical personnel can access into the system and the databases. Therefore, in one center or a hospital, there will be several computers involved for the nurses and doctors to obtain the information and modified them accordingly. Local Area Network (LAN) is utilized between the local server and the PCs for easy offline data sharing between those computers. When the data is stored into the local server which manages the local database, they will also be uploaded to the cloud database. Hence, data sharing between hospitals and dialysis centers is established. As for the mobile application, the system can be accessed by both medical personnel and dialysis patients, however administrative features are granted to the personnel only to ensure the data protection and integrity. The patients are limited to view their own medical information and they can present this information with their own consent in any emergency case or if they are travelling somewhere far from their regular dialysis center or hospital just by using the application.

\section{PREVIOUS WORK}

RFID technology offers a great deal of benefits to numerous industries including the healthcare industry. The application of this technology can be extremely beneficial as it can be utilized for patient identification, medical equipment tracking and tracing, efficiencies in patient care, etc. There are various types of operating frequency in RFID system which are Low Frequency (LF), High Frequency (HF) and Ultra-High Frequency (UHF). Each of this frequency has its own characteristics and it is important to select the suitable frequency for one's application. Table 2 below outlines the differences between these three standard operating frequencies.

TABLE 2

CHARACTERISTICS OF RFID THREE STANDARD OPERATING FREQUENCIES [5]

\begin{tabular}{|c|c|c|c|}
\hline FREQUENCYRANGE & $\begin{array}{l}125 \mathrm{KHZ} \\
\text { (LOW) }\end{array}$ & $\begin{array}{l}\text { 13.56MHZ } \\
\text { (HIGH) }\end{array}$ & $\begin{array}{l}\text { 868.95@IHZ, } \\
\text { (IUTRA-HIGH) }\end{array}$ \\
\hline $\begin{array}{c}\text { Typical Max Read Range } \\
\text { (Passive Tags) }\end{array}$ & $<0.5 \mathrm{~m}$ & $\sim 1 \mathrm{~m}$ & $\sim 3 \mathrm{~m}$ to $\sim 10 \mathrm{~mm}$ \\
\hline General Characteristics & $\begin{array}{l}\text { - Relatively expensive, even at high } \\
\text { volumes. } \\
\text { Low fiequency requires a longer } \\
\text { more expensive copper antenna. }\end{array}$ & 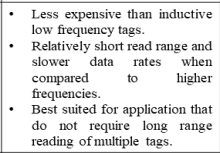 & $\begin{array}{l}\text { - In large volumes, UHF tags } \\
\text { have the potential for being } \\
\text { cheaper than LF and HF tagss. } \\
\text { capable of reading multiple } \\
\text { tags quickly. }\end{array}$ \\
\hline Tag Power Source & $\begin{array}{l}\text { - passive tags only (inductive } \\
\text { coupling) }\end{array}$ & $\begin{array}{l}\text { - passive tags only (inductive or } \\
\text { capacitive coupling) }\end{array}$ & $\begin{array}{l}\text { - Active tags with integral } \\
\text { battery or passive tags using } \\
\text { capacitive, E-field coupling. }\end{array}$ \\
\hline Data Speed & Slow & Medium & Fast \\
\hline Typical Applications & $\begin{array}{l}\text { : } \\
\text { Access control } \\
\text { - Animal tracking, } \\
\text { Vehicle immobilizers }\end{array}$ & $\begin{array}{l}\text { : Smart Cards, } \\
\text { Item-level tracking including } \\
\text { baggage handling (Non-US). } \\
\text { tiroraries }\end{array}$ & $\begin{array}{ll}\text { Pallet tracking } \\
\text { Electric toll collection } \\
\text { Baggage handling (US) }\end{array}$ \\
\hline
\end{tabular}

In the research carried out by Ahsan-uz-Zaman et Al. [6], they had developed a Low Frequency (LF) RFID integrated system that can track test tubes of samples in hospital laboratory. 
The system made use of RFID tags in which they represent the referral number of the tubes. This system completely removed the conventional documentation method, which is typing as well as authentication method, making the system more efficient and less prone to security risks and human errors. A PC with a centralized web-based database was installed for monitoring and management purposes.

Park et Al. [7] conducted a research study on a healthcare system that was incorporated with RFID technology, web-based technology and mobile technology. RFID was used to provide remote medical services, patients identification and it was utilized to track issued prescription, eliminating illegal billing issues. Mobile devices were responsible in handling the remote medical services in which SMS technology was implemented whereas the web-based technology was used to help the user to manage the prescription system in a more secured way such that the data management system was only accessible with passwords.

A monitoring system for patient health condition via a mobile phone was designed by a team of researchers from Universiti Sains Malaysia (USM), Malaysia [8]. The application was implemented with RFID technology, Zigbee module and GSM technology. It provides a better means of communication between the patients and the doctors. A doctor would receive an SMS containing the status of the patients in the hospital and this could be handy in any case of emergency as the doctor can attend the patient as soon as possible. RFID that is integrated with wireless sensor networks WSN allows more information to be obtained in which this includes the measurement of temperature and physiological signals.

It must be highlighted that the previous works [6][7][8] are almost similar to the current research in terms of transforming the paper-based data collection method to a digital platform. This is achieved by integrating RFID technology with a Database Management System (DBMS). Additionally, the current research has its own mobile application that can be accessed via a mobile device interface. One of the main contributions of the current research is to utilize mobile application technology instead of GSM and SMS technology. Park et Al. [7] noted that the data can be accessed through the system interface only with passwords. Similarly, the current system also uses this approach for its PC and mobile GUIs. In this system, the GUIs have a login form which can detect and differentiate the users as to what data they can access. This means that only specific data can be accessed by registered users such as dialysis patients while authorized administrators such as medical personnel would have full control access over the data. As for the frequency selection of the RFID system, Ahsan-uzZaman et Al. [6] mentioned the use of Low Frequency (LF) RFID system in their research which the frequency is $125 \mathrm{kHz}$ to track the test tubes. As for the E-Dialysis system, High Frequency (HF) RFID band is utilized instead as it directly concerns the lives of dialysis patients. The data reading range and the speed of the frequency band must be considered in order to avoid any delay in tag scanning on RFID reader while providing treatment to the dialysis patients. Not only that, it is to ensure the security of the medical information. Table 2 claimed that the Low Frequency band $(125 \mathrm{kHz})$ has the slowest data speed among the three standard operating frequencies, even though it has the shortest reading range. Hence, it is not suitable for the current research in terms of tag detection range, speed and performance.

The database development of the current research has almost identical method as the one presented by Mehra et Al. [9] They proposed a medical database that comprises drug prescription, sensitive drugs and specific allergies of the patients. Similar to the E-Dialysis system, RFID technology was implemented for digitizing the whole process and security purposes in which unique RFID identification number were utilized and only authorized personnel can have access on the data. Besides that, the authors stated the patient data is stored in online database, to which the E-Dialysis system also comprises of online or cloud database, but with an addition of local database which allows an offline access to the medical information in the hospital or dialysis center with the use of Local Area Network (LAN).

\section{RESULT}

This section is divided into three parts which explain the completed development of the system hardware, the backend and also the frontend of the system for both PC-based platform and mobile application.

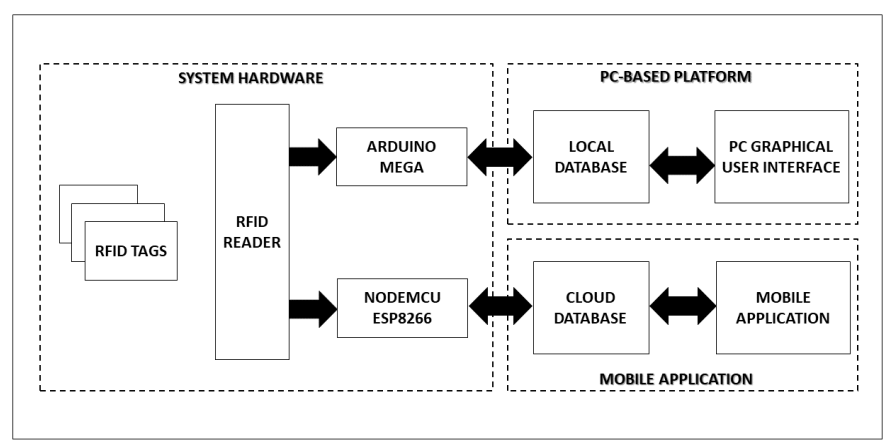

Fig. 2 Block Diagram of E-Dialysis System

\section{A. Design of System Hardware for Both PC-Based and Mobile Application}

At the present time, the development of system hardware for both PC based platform and mobile application has been completed. The RFID system which encompasses a High Frequency (HF) MFRC522 RFID reader and passive tags integrated with the microcontrollers; Arduino Mega and NodeMCU ESP8266, which can be seen in Figure 3 and Figure 4 respectively, are successfully developed.

In this development, each RFID tag acts as an identification tag for the dialysis patients in which it carries a unique serial number. This serial number is linked to the databases upon the registration of a new user. When the tag is scanned on the RFID reader, the microcontrollers, which are Arduino Mega and NodeMCU ESP8266, fetch the necessary information that is linked to the serial number. Both Arduino Mega and NodeMCU ESP8266 have been programmed accordingly to ensure that the RFID reader can identify relevant dialysis patients' RFID tags, collect the data, upload and download them into and from the databases respectively. 


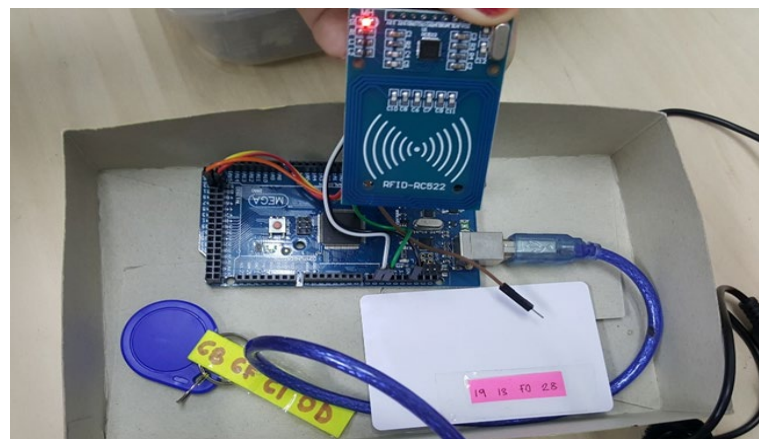

Fig. 3 Arduino Mega Setup with RFID System for PC-based Platform

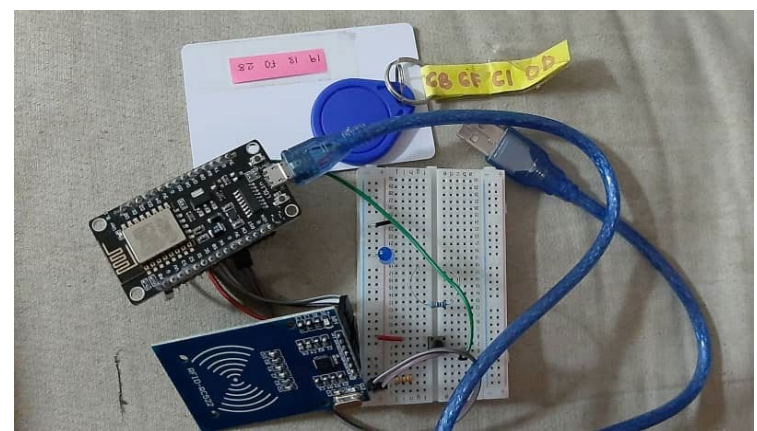

Fig. 4 NodeMCU ESP8266 Setup with RFID system for Mobile Application

Both platforms use the same specifications of RFID reader and tag which operates at $13.56 \mathrm{MHz}$ of High Frequency (HF) band, making the signal reading range especially ideal for the patient information identification and tracking. The short signal range provides an advantage to the security of the whole system as it eliminates any unauthorized or attempted access to the information unless the RFID tags are in the scanning range of $3 \mathrm{~cm}$.

Another important property of the RFID system in this research is the medium speed of the data transfer rate. Speed rate and signal reading range are directly proportional to the frequency. A low frequency radio signal will travel very slow in a very short range. Therefore, this would cause a delay in obtaining the patient's information which affects the dialysis treatment process or any sudden emergency case. While an ultrahigh frequency radio signal will travel fast, it would travel in a broad range. Hence, the frequency is not suitable for medical data protection.

An experiment was conducted to evaluate the performance test between the High Frequency (HF) MFRC522 RFID reader and its tag. According to the product datasheet of MFRC522 [10], the typical operating distance of the module is up to $50 \mathrm{~mm}$ or $5 \mathrm{~cm}$ depending on the antenna size and tuning. A digital caliper was used as a measuring tool to inspect the travel distance of the radio signal from a High Frequency (HF) RFID tag to the RFID reader in unit millimeter ( $\mathrm{mm})$ and the speed rate was observed. The constant variables are the frequency of RFID reader and its tag which operates at $13.56 \mathrm{MHz}$ and the same tag was used in five different distances. The results were compiled as shown in Table 3.
TABLE 3

PERFORMANCE TEST OF HIGH FREQUENCY (HF) READER AND TAG

\begin{tabular}{|l|c|c|}
\hline \multicolumn{1}{|c|}{ Distance of RFID Tag from RFID Reader (mm) } & Tag Detection & Speed Rate (s) \\
\hline $10 \mathrm{~mm}$ & Yes & <1s \\
\hline $20 \mathrm{~mm}$ & Yes & \\
\hline $30 \mathrm{~mm}$ & Yes & \\
\hline $50 \mathrm{~mm}$ & No & \\
\hline
\end{tabular}

Based on the performance test conducted, the radio signal between the High Frequency (HF) reader and the tag can travel up to $30 \mathrm{~mm}$ or $3 \mathrm{~cm}$ only and the speed rate is less than 1 second, making it the most suitable for the system in terms of performance and security.

\section{B. Development of E-Dialysis DBMS and GUI for PC-Based Platform}

As illustrated in Figure 2, this part presents the accomplished development of backend and frontend of the PC-based platform. The backend system began with XAMPP, a hosting software platform. It was used to create a local server between PC and the database. The control panel of this platform has four primary components but for the database development, only two were utilized which are Apache and MYSQL modules; see Figure 5. With XAMPP, the MYSQL database is successfully created with the help of phpMyAdmin. In its relational database, it comprises about 25 attributes which are to be filled by the user which include personal information, medical information and records such as full name, national identification card, unique number of RFID tag, home address, medical records, history of diagnosis treatment and blood test examination results; as pictorially depicted in Figure 6 . The connection of this local database to both RFID system and the PC Graphical User Interface (GUI) has been established, hence the data fetched from the database can be displayed on the GUI created. 


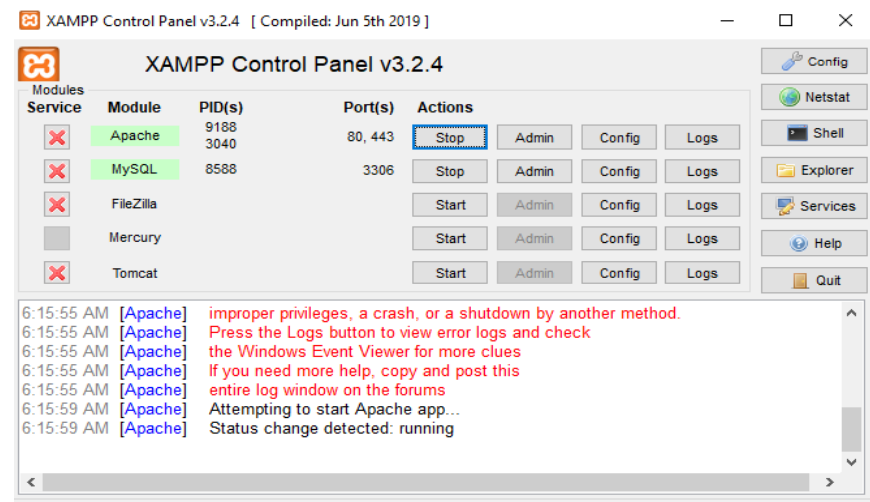

Fig. 5 XAMPP Control Panel as Local Server

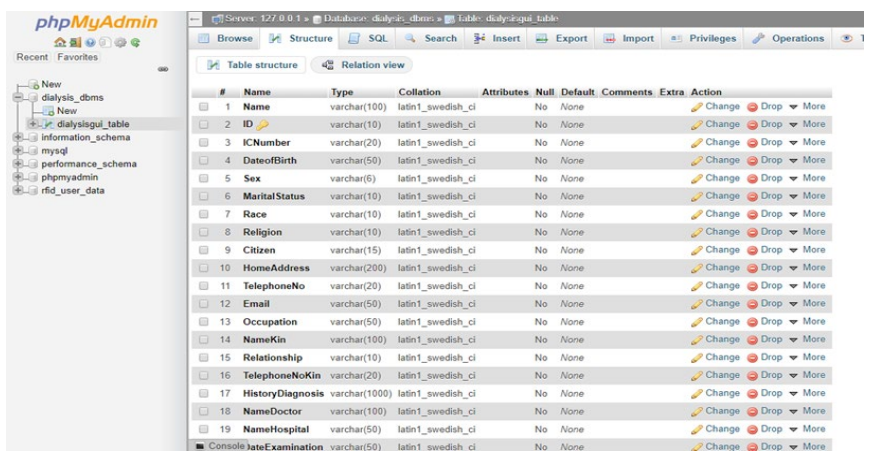

Fig. 6 Local Database of PC-based Platform

As for the PC-based system frontend, The PC Graphical User Interface (GUI) is created with Visual Basic. Figure 7 displays the design of the GUI that has a main menu comprising four panels. The panels are connection panel, patient data panel, registration and modification panel, and lastly patient records panel. Each panel differs in functions and they are connected to RFID system and local database.

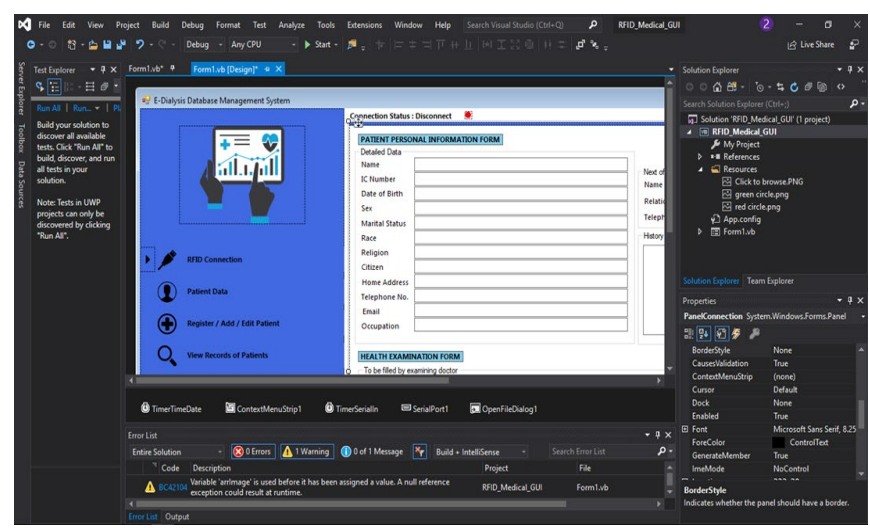

Fig. 7 GUI Design with Visual Basic

As illustrated in Figure 8, the RFID connection panel is the first panel a user will access to when the GUI is opened. An established connection between the GUI and RFID is necessary to ensure the user's accessibility to other panels. Otherwise, it will prompt the user to re-confirm the connection; as presented in Figure 9.

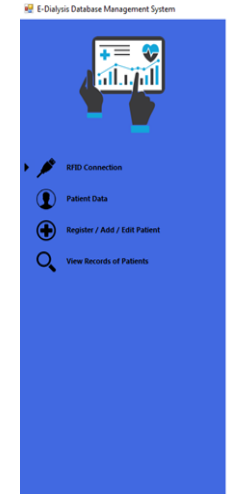

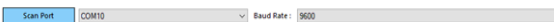

Fig. 8 Panel Menu of Successful RFID Connection

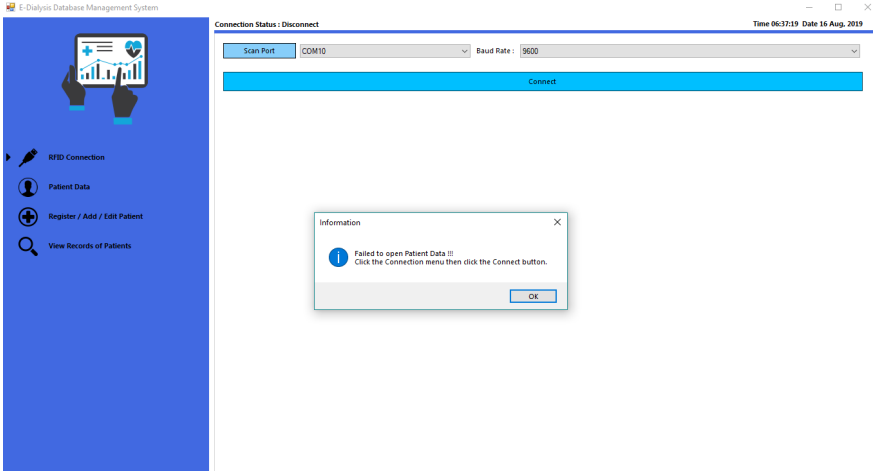

Fig. 9 Panel Menu of Unsuccessful RFID Connection

The second panel; as shown in Figure 10, is the patient data panel where a user is able to view a form of dialysis patient information including the personal information, photo of the patient, medical records such as urine test results, blood test results and history of diagnosis and treatment. This panel enable the user to scan the RFID tag to the RFID reader, and subsequently fetch the accurate data. The data will be displayed accordingly; as demonstrated in Figure 11. Thus, instead of typing and searching specific IC numbers or names that could take a lot of time, this panel offers an immediate and automatic searching tool for the data within seconds.

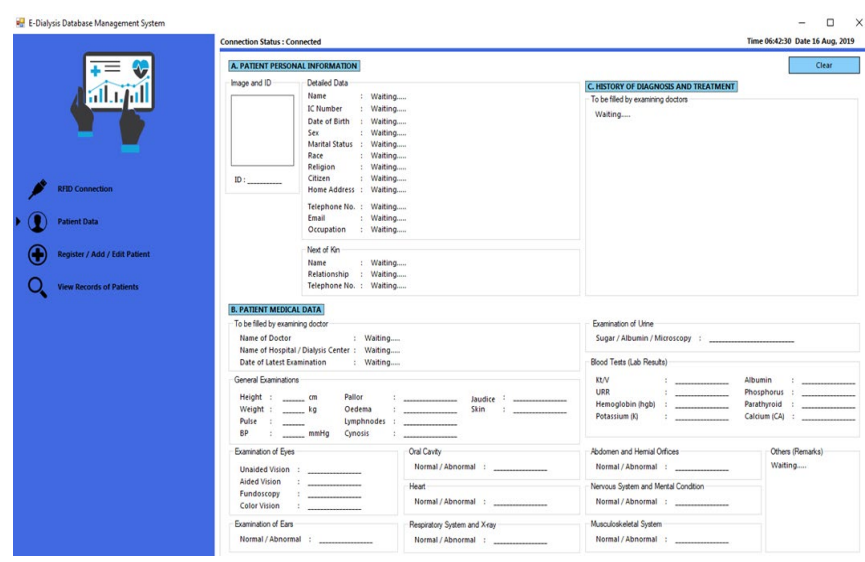

Fig. 10 Panel Menu of Patient Data 


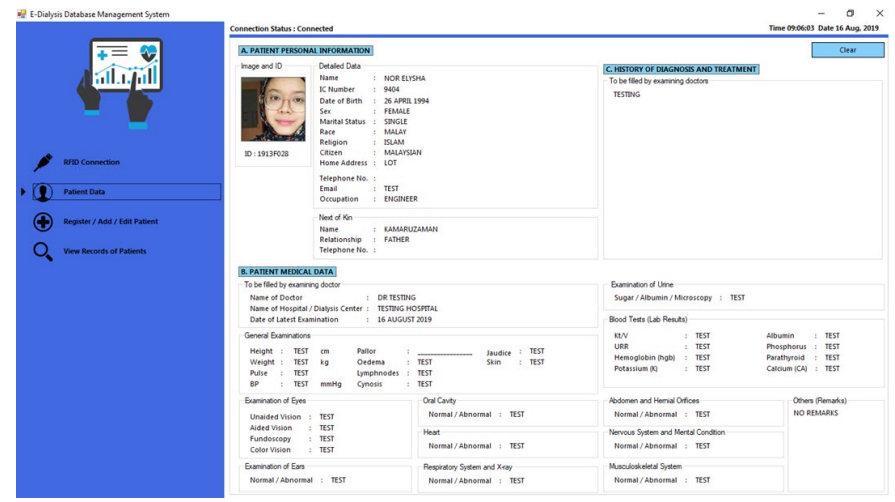

Fig. 11 Panel Menu of Fetched Patient Data

Next, Figure 12 shows the third panel, which offers the registration and modification features. A user can use the form in the panel to register new patient and edit any existing patient information. This panel also has the similar capability like the second panel where it can fetch information from the database with the help of RFID technology. For a new patient registration, when a new RFID tag is issued and scanned on the RFID reader, the form will be blank, however it will fetch the unique number of the tag so that new information will be stored under that number. As for the editing of existing patient information, the panel will fetch the existing information and display them on the form. The user is allowed to edit and update them accordingly.
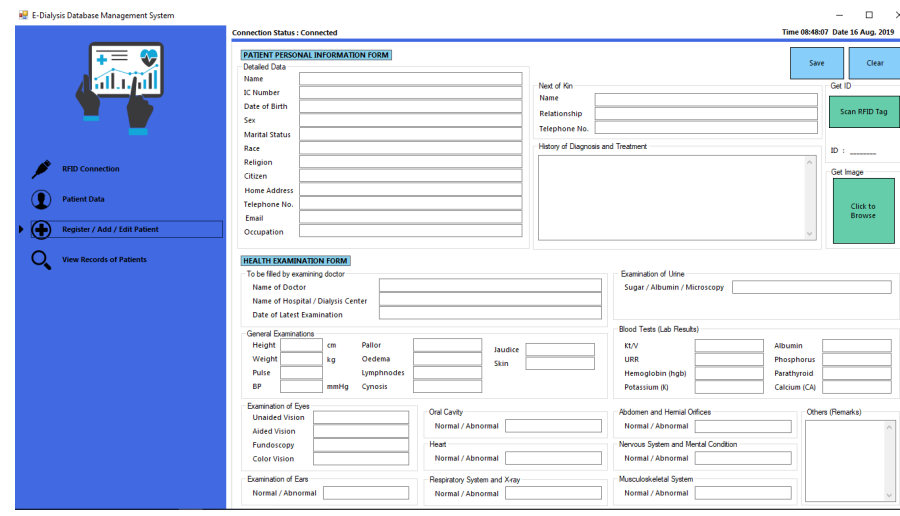

Fig. 12 Panel Menu of Blank Register/Add/Modify Form

The last panel displays the patient records. It is actually the database itself but in a more user-friendly way where a user can access and view all registered patient information. Besides, this panel provides a feature where a user is given three options to search for specific patient information which are name, ID and IC. This is illustrated in Figure 13 and Figure 14.

Even though the PC GUI has been successfully completed, a login form must be added. Some panels must be limited only to administrators such as medical staffs of dialysis centers and hospitals. The login form will be able to differ be two account types in this system which one is for the administrator and the other one is for patient. An administrator account will have full access on patients' information and medical data and this account is permitted to modify them. As for the patient account, a patient can only access his or her own personal data and medical records and cannot modify any of them. This is the security measure for the proposed system so that medical data is always accurate and truthful.

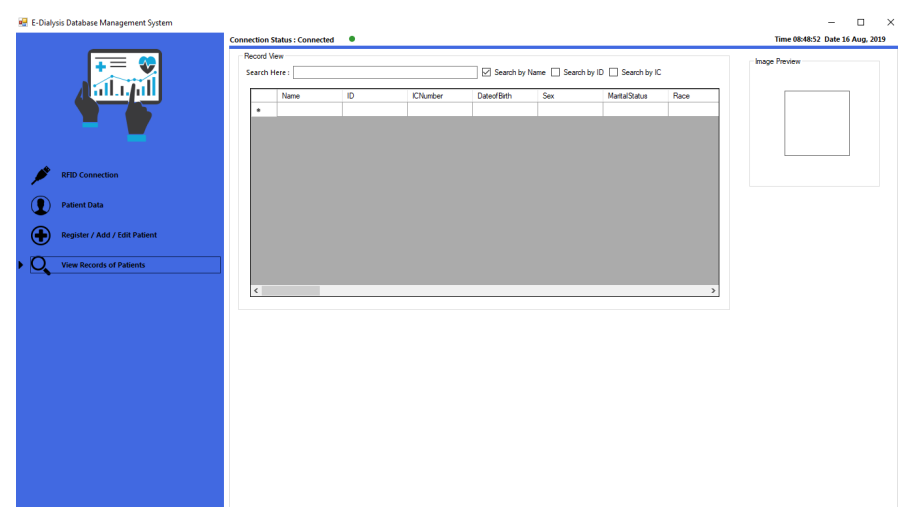

Fig. 13 Panel Menu of Unavailable Patients' Records

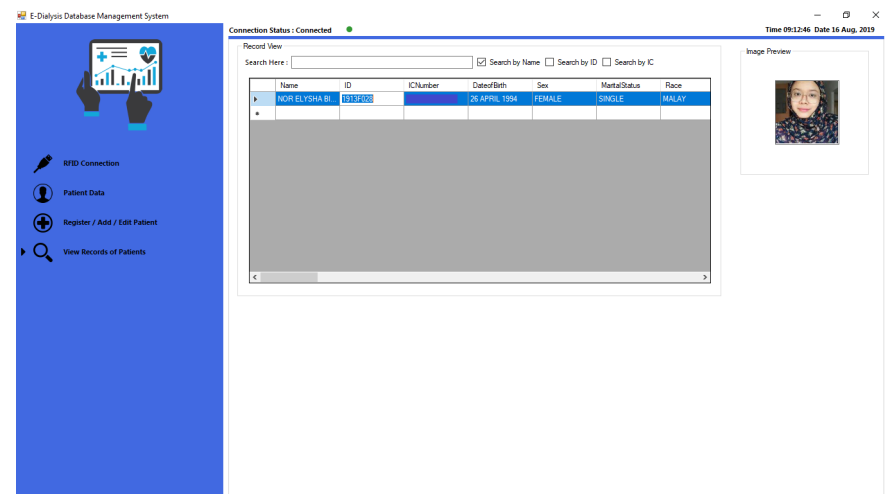

Fig. 14 Panel Menu of Available Patients’ Records

\section{Development of E-Dialysis DBMS and GUI for Mobile Application}

Refer to the block diagram in Figure 2, this part elaborates the finished results of developing the backend and frontend for the mobile application. The cloud database, which was created by using Google Spreadsheets, had been implemented as the platform database; see Figure 15. The attributes of this database are similar to the database attributes that were created for the PC-based platform.

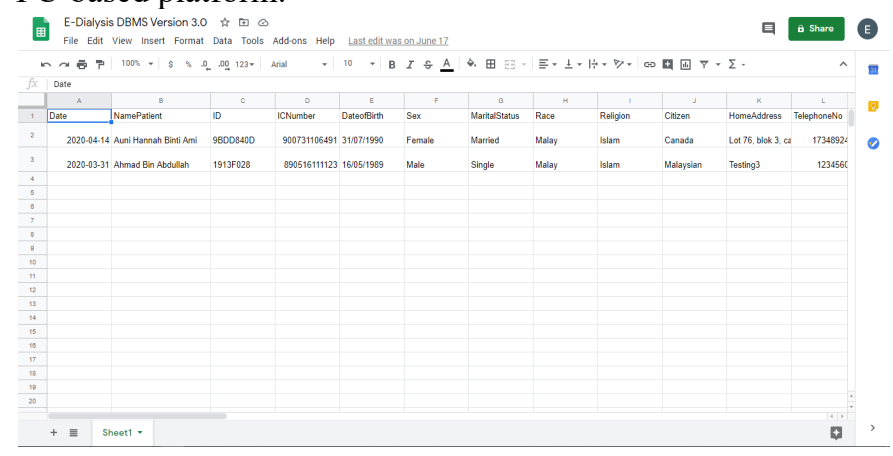

Fig. 15 Google Spreadsheet as Cloud Database

Communication between the cloud database and the NodeMCU ESP8266 has been established by using Application Programming Interface (API) to ensure data exchange between them. API, as shown in Figure 16, was created in the script editor tool of Google Spreadsheets. 


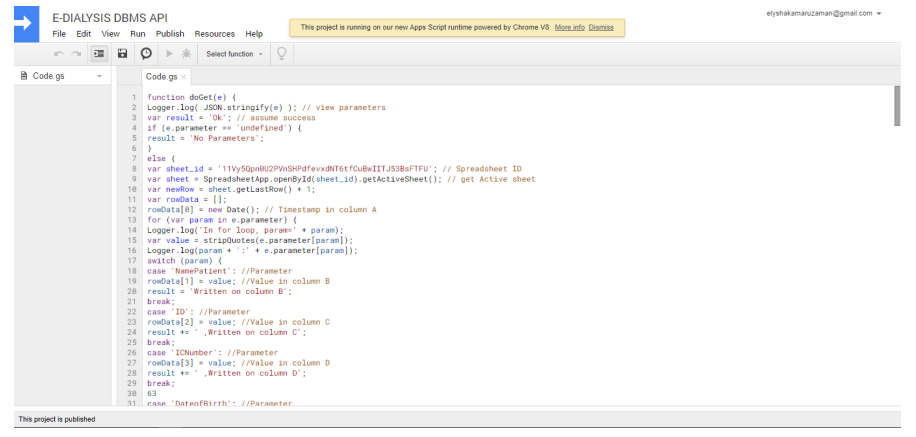

Fig. 16 Creating API in Script Editor Tool

The API is then deployed as a web application that comprises the web app URL. This URL is needed in order to use the Pushing Box service whereby this service pushes the existing data created into the cloud database when the RFID reader is scanned with an already registered RFID tag. As illustrated in Figure 17, a scenario to send data was created for the data push purpose. Once the scenario is tested, the data will be pushed, and it will prompt the user that the data is successfully pushed into the database, as demonstrated in Figure 18 and Figure 19 respectively.

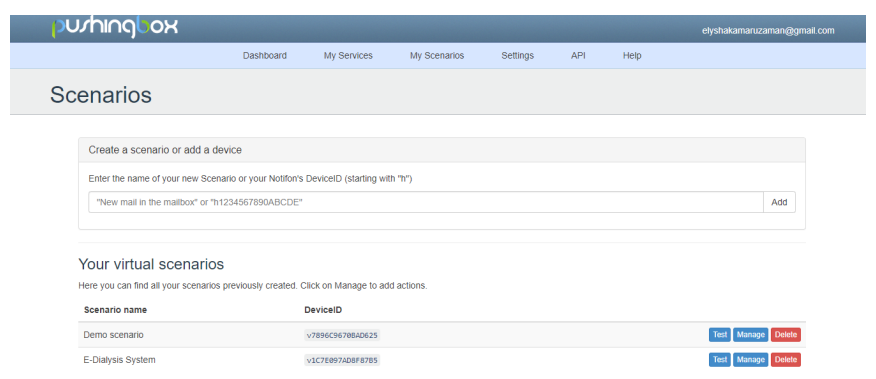

Fig. 17 Creating a Scenario using Pushing Box Service

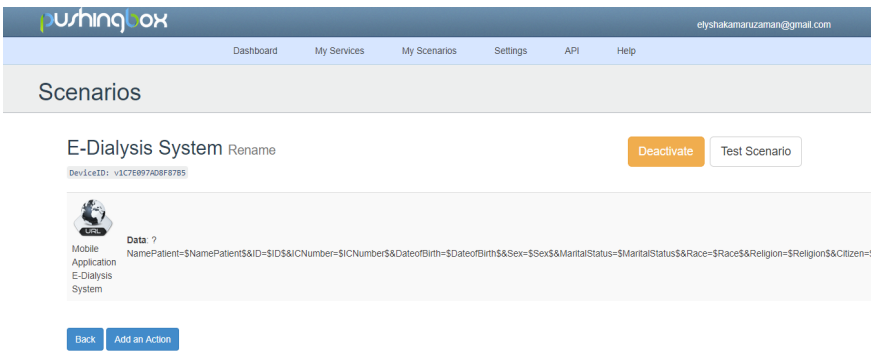

Fig. 18 Test Scenario to Push Data

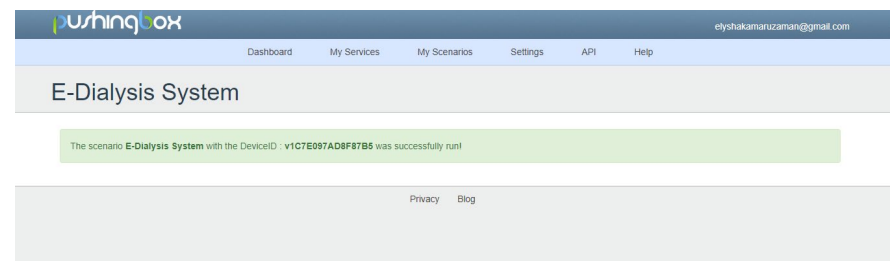

Fig. 19 Scenario's Successful Run

Next, the GUI for mobile application has been designed and developed with AppSheet in which it is linked with the cloud database; Google Spreadsheet and the NodeMCU ESP8266 microcontroller. Figure 20 displays the design of login system for the mobile application. For the purpose of data privacy, the user needs to fill in their registered email and password in order to access into the system. Figure 21 and Figure 22 show the similar interface as the PC-based platform in which they are panels for patient registration, editing and viewing the medical records.
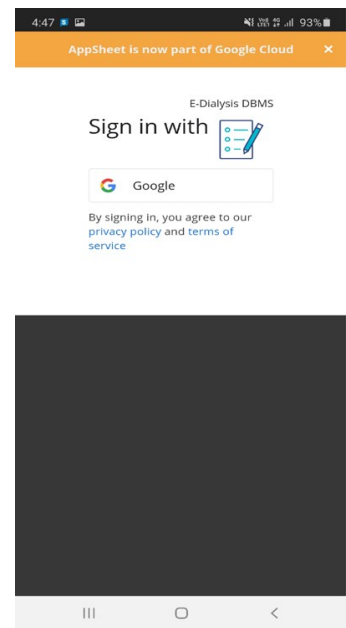

Fig. 20 Mobile Application Login System

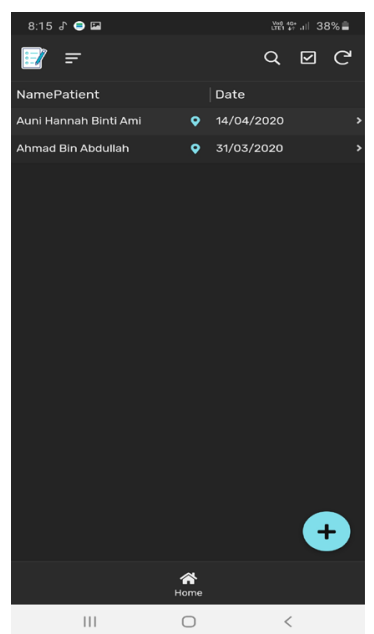

Fig. 21 View Overall Medical Records Page

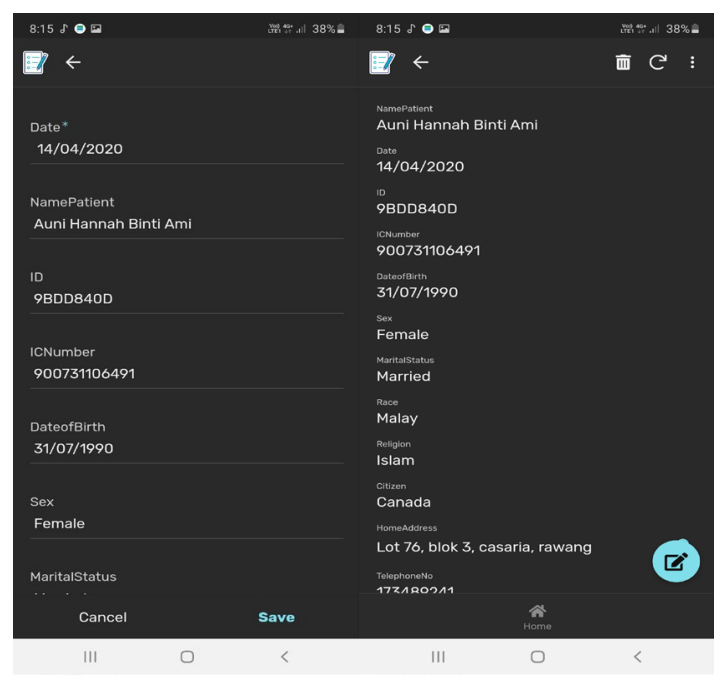

Fig. 22 Patient Registration and Editing Page 


\section{CONCLUSION}

In a summary, the research objectives have been achieved and dialysis monitoring system integrated with Database Management System (DBMS) using RFID technology has been created. The system is mainly to improve both dialysis patients and medical personnel' experience in providing treatment to their patients. It will also provide secured environment for both patients and personnel whenever they are using the system. The information of dialysis patient such as dialysis record and medical history is stored within an RFID tag, allowing medical personnel to perform a more efficient diagnosis, hence preventing clinical errors. Other than that, RFID technology has become a life-saving solution for the smallest percentage of dialysis patients who have disabilities or complications. It also surely assists the patients especially in the times of emergency. With an RFID reader connected to local and online or cloud databases, the medical personnel and the patients can easily access to the information through the two platforms which are PC and mobile application. This system can be handy for the dialysis patients who must go travel occasionally as they can go to any dialysis center to get the appropriate treatments.

\section{REFERENCES}

[1] Bujang M. A., Adnan T. H., Hashim N. H., Mohan K., Kim Liong A., Ahmad G., Goh B. L., Bavanandan S., Haniff J. (2017). Forecasting the Incidence and Prevalence of Patients with End-Stage Renal Disease in Malaysia up to the Year 2040. International Journal of Nephrology, 2017, pp.1-5, 2017.

[2] Ismail, H., Abdul Manaf, M. R., Abdul Gafor, A. H., Mohamad Zaher, Z. M., \& Nur Ibrahim, A. I. (2019). Economic Burden of End-Stage Renal Disease to the Malaysian Healthcare System. Kidney International Reports, pp.1, 2019.

[3] Ghazali A, Lim YN, Goh BL, Wong HS, Liu WJ, Lee ML, Phillip NJ, A Halim, Lee WT, Clare Tan HH, Shahnaz S, Sunita B, Rosnawati Y, Lena Yeap, Lee DG, "24th Report of the Malaysian Dialysis and Transplant Registry 2016", The National Renal Registry, Malaysian Society of Nephrology, pp. 1 - 48, 2018.

[4] "Retirement age", En.wikipedia.org, 2018. [Online]. Available: https://en.wikipedia.org/wiki/Retirement_age. [Accessed: 16- Oct- 2018]

[5] COMPARISON TABLE REFERENCE

[6] K. Ahsan-uz-Zaman, K. Ullah, O. Tasin and M. Kabir Milon, "RFID Based Hospital Laboratory Automation System", 2017 2nd International Conference on Electrical \& Electronic Engineering (ICEEE),2017.

[7] Joo-Hee Park, Jin-An Seol and Young-Hwan Oh, "Design and implementation of an effective mobile healthcare system using mobile and RFID technology," Proceedings of 7th International Workshop on Enterprise networking and Computing in Healthcare Industry, 2005. HEALTHCOM 2005., Busan, South Korea, pp. 263-266, 2005.

[8] N. Renuka, C. Ng and W. Ismail, "Embedded RFID tracking system for hospital application using WSN platform", 2013 IEEE International Conference on RFID-Technologies and Applications (RFID-TA),2013.

[9] Mehra, V., Sarvari, P. and Ruban, N,."RFID Based Secured, Remotely Accessible Personal Medical Data Base Including the Medicinal History", 2018 4th International Conference on Computing Communication and Automation (ICCCA), pp.1 - 4, 2018.

[10] Nxp.com. 2016. MFRC522 Standard Performance MIFARE And NTAG Frontend. [online] Available at: $<$ https://www.nxp.com/docs/en/datasheet/MFRC522.pdf> [Accessed 1 November 2020]. 